
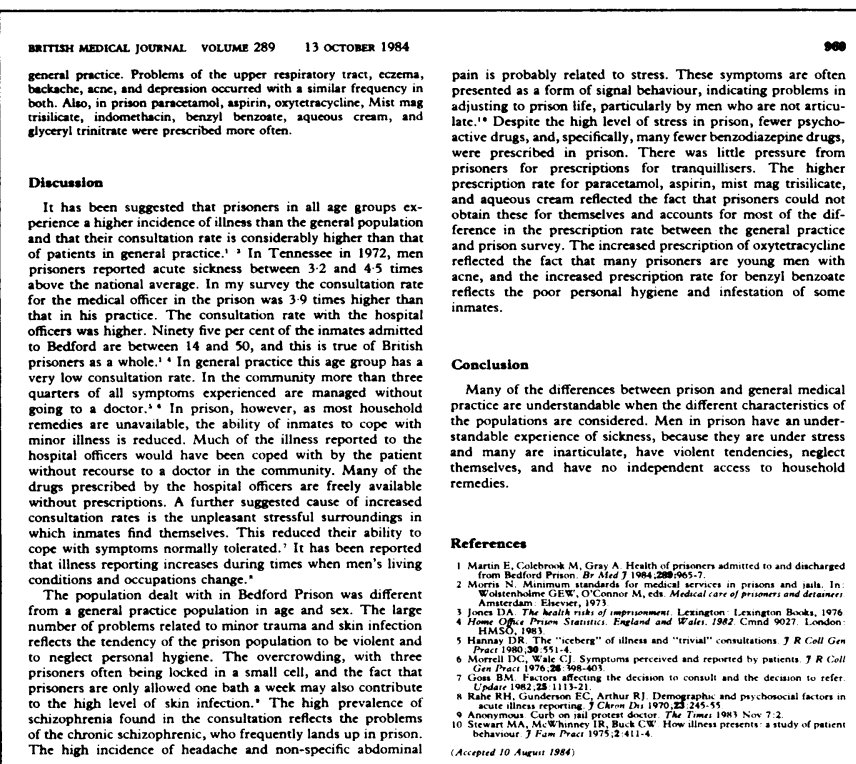

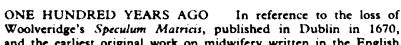
and the carlicst orizinal work on midwifery written in the English

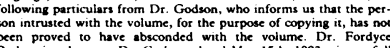

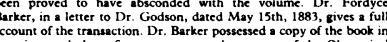

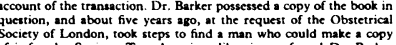

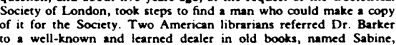

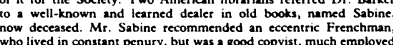

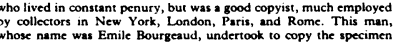

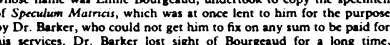

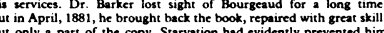

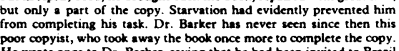

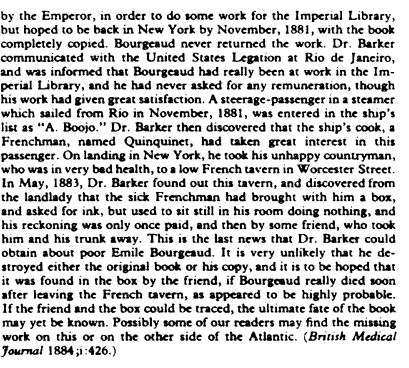

970

BRTTISH MEDICAL JOURNAL VOLUME $289 \quad 13$ OCTOBRe 1984

\section{Life Changes}

\section{Menopause: associated problems}

JEAN COOPE

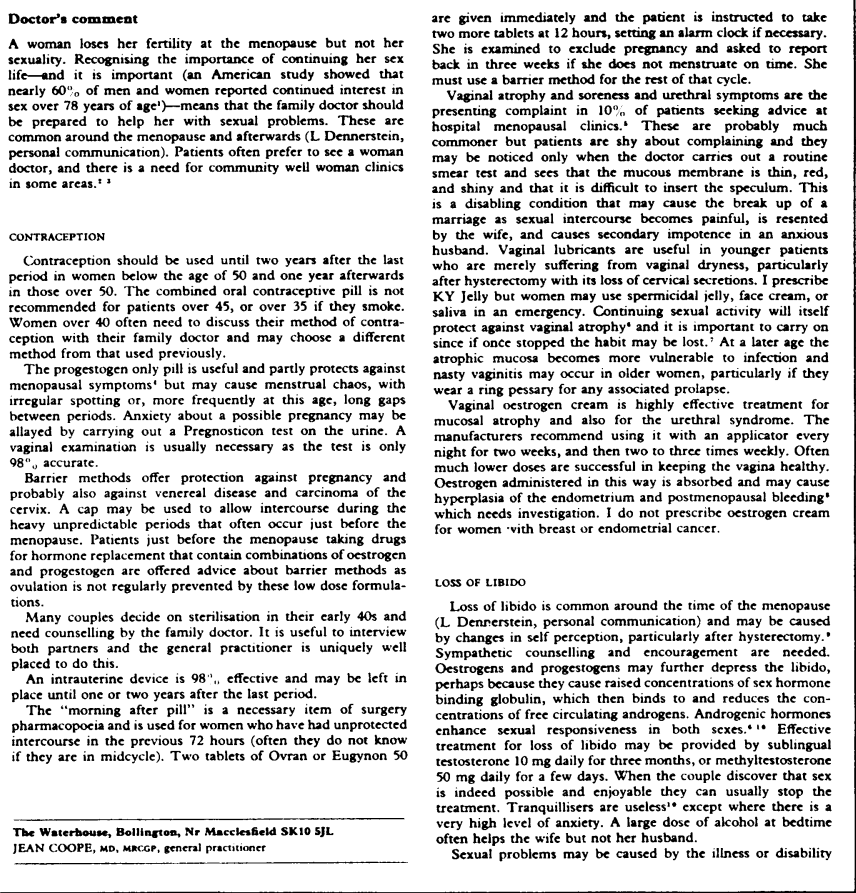

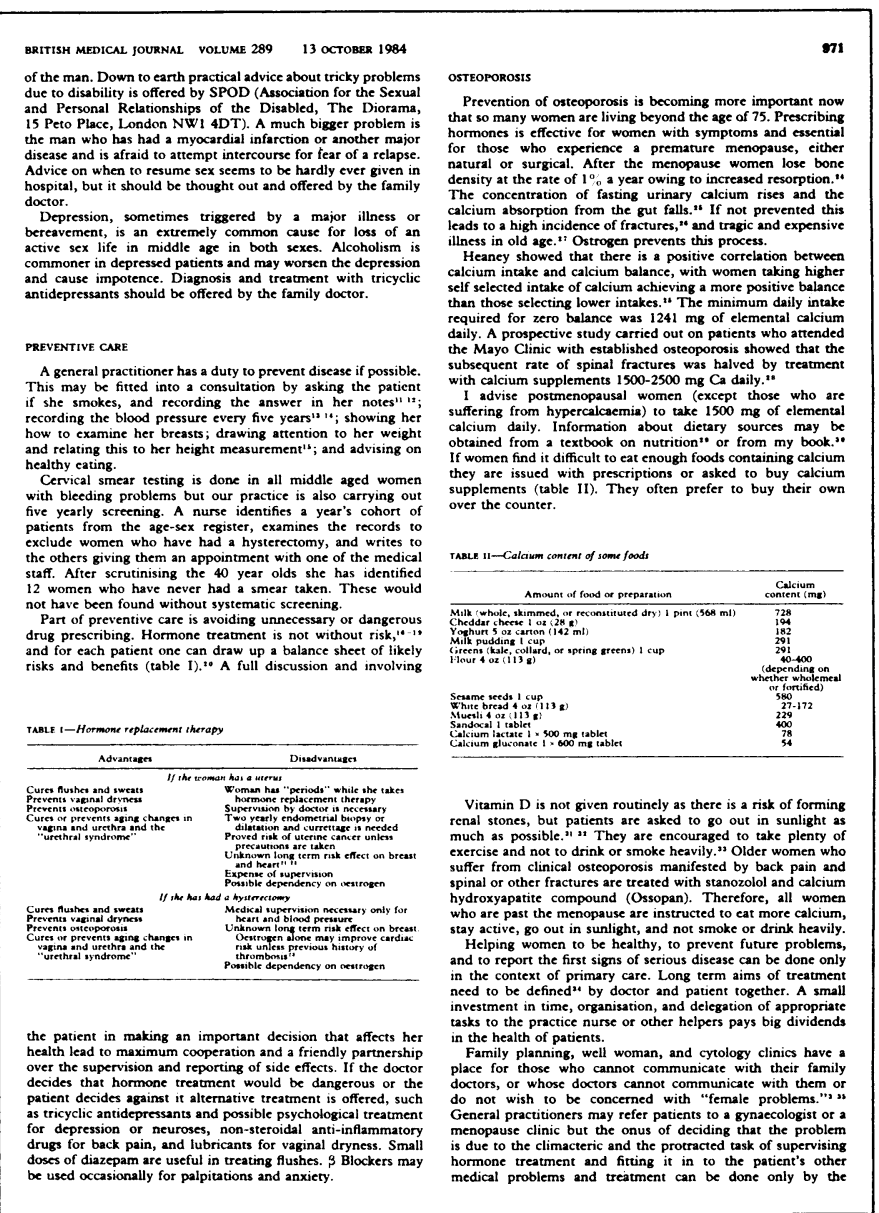

972

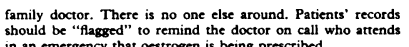

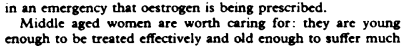

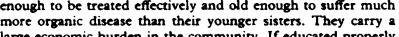

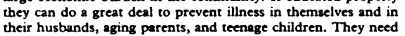

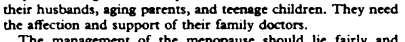

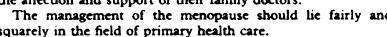

Referencest

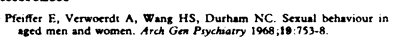

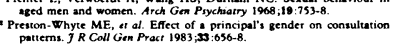

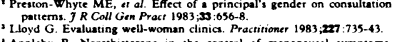

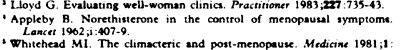

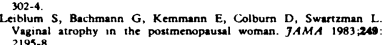

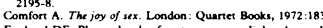

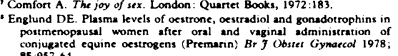

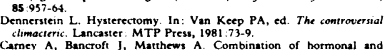

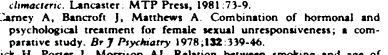

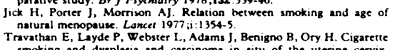

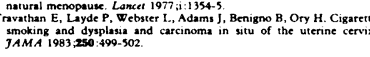

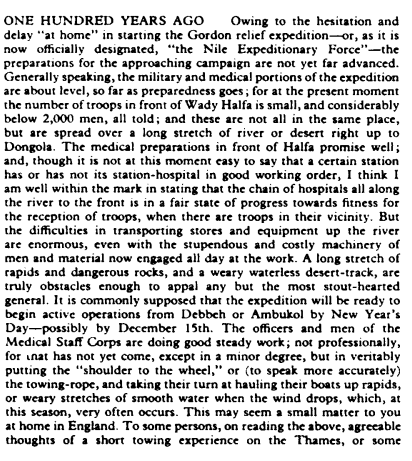

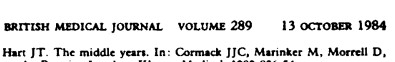

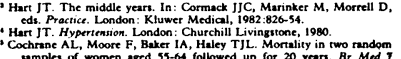

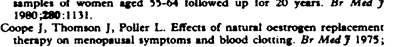

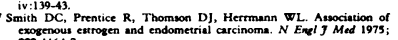

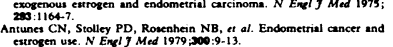

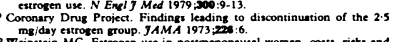

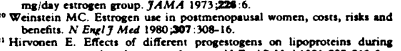

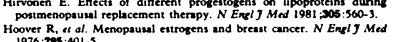

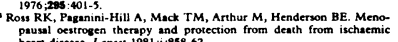

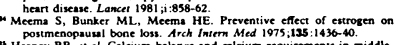

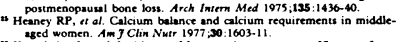

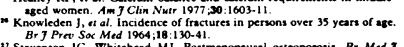

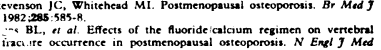

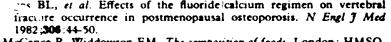

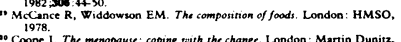

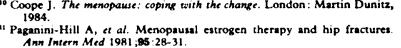

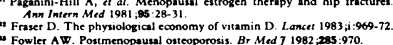

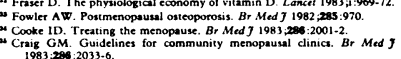

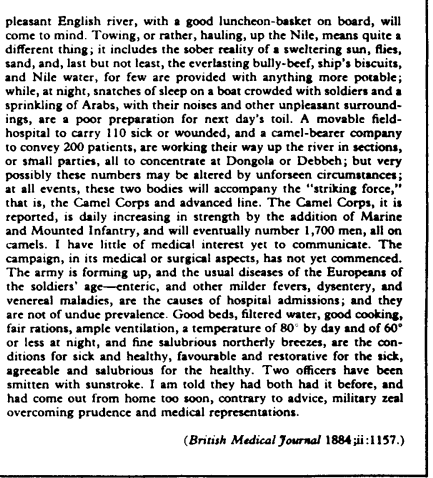

